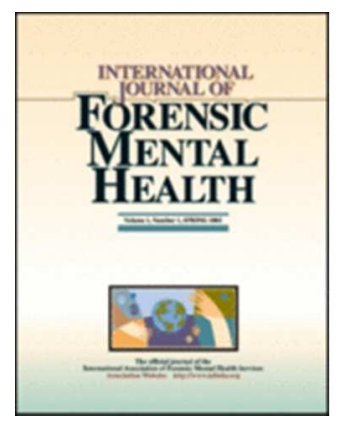

\title{
Subtypes of severely mentally ill violent offenders in a Spanish Forensic Psychiatric Hospital
}

\begin{tabular}{|r|l|}
\hline Journal: & International Journal of Forensic Mental Health \\
\hline Manuscript ID: & UFMH-2013-032.R3 \\
\hline Manuscript Type: & Original Article \\
\hline Keywords: & Schizophrenia, Violence, Conduct Disorder, HCR-20, PCL:SV \\
\hline \multicolumn{3}{c}{ SCHOLARONE } \\
\multicolumn{3}{c}{ Manuscripts }
\end{tabular}


Title: Subtypes of severely mentally ill violent offenders in a Spanish Forensic 2 Psychiatric Hospital

4

11 Men with SMI + CD present a challenge to forensic psychiatric services.

3

4

(5)

(8)

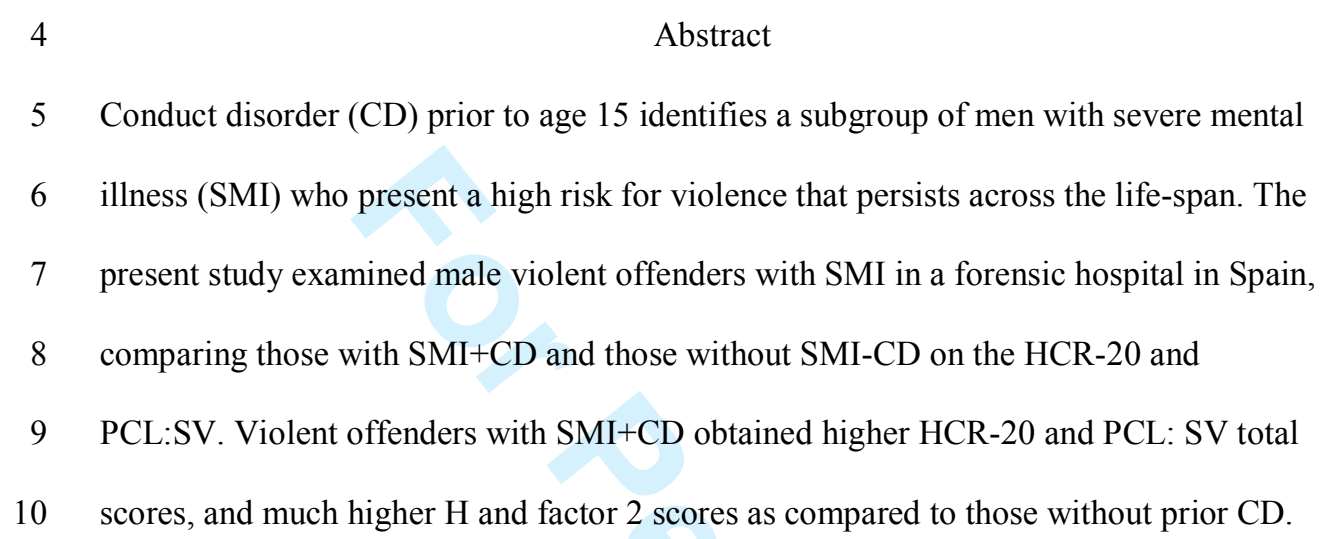

5 Conduct disorder (CD) prior to age 15 identifies a subgroup of men with severe mental

6 illness (SMI) who present a high risk for violence that persists across the life-span. The

7 present study examined male violent offenders with SMI in a forensic hospital in Spain,

8 comparing those with SMI $+\mathrm{CD}$ and those without SMI-CD on the HCR-20 and

9 PCL:SV. Violent offenders with SMI+CD obtained higher HCR-20 and PCL: SV total

10 scores, and much higher $\mathrm{H}$ and factor 2 scores as compared to those without prior $\mathrm{CD}$.

5

26


27 28

\section{INTRODUCTION}

There is robust evidence that among violent offenders with severe mental illness (SMI), the age of onset of antisocial and aggressive behaviour defines sub-types with distinctive features and risk of recidivism (Hodgins, 2008). Those who commit most offences present Conduct Disorder (CD) prior to age 15. Others with no childhood history of conduct problems begin engaging in aggressive behaviour as illness onsets. A small group with no prior history of aggressive behaviour engages in serious violence, usually against a care-giver, after many years of illness.

Among men with schizophrenia, those with a history of $\mathrm{CD}$ prior to age 15 , are convicted for more non-violent and violent crimes (Crocker et al., 2005; Fulwiler \& Ruthazer, 1999; Mueser, Crocker, Frisman, Drake, Covell, \& Essock, 2006), commit a more diverse array of crimes (Hodgins, 2004), and have criminal histories similar to those of non-mentally ill offenders who also have a childhood history of conduct problems (Hodgins \& Côté, 1993; Schug, Raine, \& Wilcox, 2007). In addition, almost all display a pattern of substance misuse going back to early adolescence (Fulwiler, Grossma, Forbes, \& Ruthazer, 1997). In a prospective investigation that followed a Dunedin, New Zealand birth cohort to age $26,40 \%$ of the cohort members who developed schizophreniform disorders had displayed CD prior to age 15 (Kim-Cohen, Caspi, Moffitt, Harrington, Milne, \& Poulton, 2003). In clinical samples of adults with schizophrenia, the prevalence of CD is lower, approximately $20 \%$, among both women and men (Hodgins, Côté, \& Toupin, 1998), but for example in a UK sample of inpatients, CD prior to age 15 characterised $42.0 \%$ of the men and $22.4 \%$ of the women with SMI (Hodgins, Cree, Alderton, \& Mak, 2008). While these samples of patients with SMI or schizophrenia 
52 were recruited in general psychiatric services, among patients in forensic services the prevalence of $\mathrm{CD}$ is higher, and among those incarcerated in correctional facilities it is further elevated (Hodgins et al., 1998).

A sample of 248 men with schizophrenia who were, on average, aged 39.8 years old at the time of the study were assessed in the two weeks before discharge from hospital using multiple sources of information including complete criminal records (Hodgins, Tiihonen, \& Ross, 2005). Fifty-two (21\%) of these men met criteria for CD prior to age 15. Incident Rate Ratios (IRR) were calculated to estimate the association between $\mathrm{CD}$ and the number of convictions for violent crimes. A diagnosis of $\mathrm{CD}$ prior to age 15 was associated with an increase of 2.29 (95\% confidence interval (CI) 1.31 $4.03)$ in the number of convictions for violent crimes after controlling for life-time diagnoses of alcohol and/or drug abuse and/or dependence. Each CD symptom present before the age of 15 was associated with a $1.15(95 \%$ CI $1.06-1.25)$ increase in the number of convictions for violent crimes, again after controlling for diagnoses of substance misuse disorders. A diagnosis of $\mathrm{CD}$ and the number of $\mathrm{CD}$ symptoms were also associated with the number of convictions for non-violent crimes. These results were replicated in a sample of UK inpatients with SMI (Hodgins, Alderton, Cree, Aboud, \& Mak, 2007). After controlling for sex, age, current alcohol and drug use, CD prior to age 15 was associated with a two-fold increase in the number of convictions for violent crimes. Again, after controlling for sex, age, and substance misuse, each $\mathrm{CD}$ symptom present before age 15 was associated with a slight increase in the number of violent crimes odds ratio (OR) 1.16, (95\% CI 1.01-1.35). Both CD diagnosis and the number of $\mathrm{CD}$ symptoms were associated with the number of convictions for nonviolent crimes. Importantly, no sex differences in the associations of CD and later offending were detected. These results concur with findings from other studies that used 
different definitions of childhood conduct problems (Fulwiler, \& Ruthazer, 1999; Rice \& Harris, 1995; Tengström, Hodgins, Grann, Långström, \& Kullgren, 2004). Both in the general population (Moffitt \& Caspi, 2001) and among people with schizophrenia, $\mathrm{CD}$ is a precursor of aggressive behaviour, as well as violent criminality. In the sample of 248 men with schizophrenia described above, the diagnosis of $\mathrm{CD}$ and the number of $\mathrm{CD}$ symptoms were associated with an increased the risk of aggressive behavior, after taking account of life-time diagnoses of alcohol abuse and/or dependence, alcohol and drug use during the follow-up period, depot medication or medication compliance, and obligatory care. The diagnosis of CD did not predict aggressive behavior, however, after controlling for life-time diagnoses of drug abuse and/or dependence diagnosis. Each CD symptom increased the risk of aggressive behavior by a factor of 1.2, and this remained significant after controlling for life-time diagnoses of alcohol and drug use disorders, self-reported alcohol and drug use, drugs detected in urine or hair or a refusal to provide a sample, depot medication or selfreported compliance, and a court order to comply with treatment (Hodgins et al., 2005). In the UK sample of men and women with SMI described above, after controlling for age, sex, and current substance misuse, $\mathrm{CD}$ diagnosis prior to age 15 was associated with an increased odds of aggressive behaviour towards others in the previous six months (odds ratio 2.66, $95 \%$ CI 1.24-5.68), as was each CD symptom (odds ratio 1.29, $95 \%$ CI 1.11-1.50) (Hodgins et al., 2008). Similar findings emerged from analyses of baseline data collected for a large trial of medications in the US. While this study used the same instrument to assess aggressive behaviour as did the previously described studies, unlike the previous studies described above, symptoms were not measured prospectively but at the same time as the aggressive behaviour. Two or more CD symptoms were found to be associated with aggressive behaviour in the previous six 
102 months after controlling for numerous other factors, and, as in the previous studies,

103 there was no association with substance misuse after taking account of childhood

104 conduct problems (Swanson et al., 2006).

105 There is little prospective research on individuals who present conduct problems

106 in childhood and who subsequently develop schizophrenia (SZ+CD). An important

107 finding has emerged from the prospective longitudinal investigation of a birth cohort in

108 Dunedin, New Zealand. As previously noted, and consistent with other epidemiological

109 evidence, the risk of violence was elevated among cohort members who developed

110 schizophreniform disorder by age 26 . This association was partially explained by the

111 presence of aggressive behaviour at ages 7, 9, and 11 and psychotic-like-experiences at

112 age 11 (Arseneault, Cannon, Murray, Poulton, Caspi, \& Moffitt, 2003). In a cohort of

113 twins aged 12 years, those reporting psychotic-like-experiences also reported

114 significantly more antisocial behaviour, depression, and anxiety (Polanczyk et al.,

115 2010). Most other relevant findings on the childhood characteristics of individuals with

116 SZ+CD derive from studies of clinical samples of adults in which data on childhood is

117 collected retrospectively from multiple sources, some objective- school, social service,

118 and juvenile justice records, and some subjective - reports from patients, parents, older

119 siblings. For example, in the sample of 248 men with schizophrenia described above,

120 more of those with, than without $\mathrm{CD}$, obtained lower than average marks in elementary

121 school, failed to graduate from secondary school, and prior to age 18 abused substances,

122 experienced physical abuse, and were institutionalised (Hodgins et al., 2005). The

123 results of other similar studies concur (Fulwiler et al., 1997; Schanda, Földes, Topitz,

124 Fliedl, \& Knecht, 1992; Tengström, Hodgins, \& Kullgren, 2001). In contrast, while

125 rates of parental criminality are elevated among men with $\mathrm{SMI}+\mathrm{CD}$, parents and 
126 siblings of men in this subgroup present similar rates of mental illness when compared

127 to those men with SMI-CD (Hodgins et al., 2005; Tengström et al., 2004).

128 Recent studies using magnetic resonance imaging (MRI) have shown that men

129 with schizophrenia preceded by CD differ in both brain activity (Joyal et al., 2007) and

130 brain structure (Schiffer et al., 2012) as compared to men with schizophrenia and no

131 history of CD. Further, some of the structural anomalies presented by those with prior

132 CD resemble anomalies of men without schizophrenia who had CD prior to age 15.

133 The accumulated evidence suggests that the presence of CD prior to age 15

134 identifies a subgroup of men with SMI who present high levels of violent offending and

135 for violent recidivism. This body of evidence on $\mathrm{SMI}+\mathrm{CD}$ has remained distinct from

136 the large body of evidence demonstrating the validity of the Historical-Clinical-Risk

137 Management-20 (HCR-20; Webster, Douglas, Eaves, \& Hart, 1997) and The Hare

138 Psychopathy Checklist: Screening Version (PCL: SV; Hart, Cox, \& Hare, 1995) in

139 predicting risk of violence and identifying factors associated with future violence. This

140 is the first study to compare severely mentally ill violent offenders with SMI+CD and

141 violent offenders with SMI-CD using these clinical tools that are commonly

142 administered in forensic psychiatric services.

143 We hypothesized that violent offenders with SMI + CD, as compared to those with

144 SMI-CD, would obtain higher HCR-20 total scores, and higher H and R scores. The

145 presence of CD prior to age 15 and high $\mathrm{H}$ scores would identify patients with SMI

146 whose antisocial and aggressive behaviours have been present since a young age and

147 that would be particularly resistant to change. Elevated R scores would suggest that the

148 long-standing pattern of antisocial and aggressive behaviour continues to be associated

149 to the higher scores on clinical tools use-to predict risk of violence. Consistent with

150 evidence showing no difference in psychotic symptoms between those with SMI $+\mathrm{CD}$ 
151 and SMI-CD, we hypothesized that the two groups of violent offenders would obtain 152 similar C scores (Hodgins, 2008). We also hypothesized that the severely mentally ill 153 violent offenders with SMI+CD would obtain higher PCL:SV scores than those with 154 SMI-CD, and that the elevation in scores would result primarily from higher factor 2 scores consistent with an earlier onset of conduct problems and a more severe pattern of antisocial behaviour. Consistent with studies of SMI+CD, we hypothesized that violent

157 offenders with SMI+CD would have been first convicted at a younger age than those with SMI-CD, that they would have been convicted or found not guilty by reason of insanity for more violent crimes, and that they would engage in more rule breaking Setting within the hospital. To test these hypotheses, we examined a sample of Spanish forensic patients with SMI who had committed violent crimes.

\section{METHOD} hospital has 375 beds. One ward includes 43 beds for females. The other three treatment wards house male patients and they differ as to level of care and supervision: one for chronic, violent patients without physical deterioration $(\mathrm{N}=117)$; one for chronic, violent patients with physical deterioration $(\mathrm{N}=80)$; and one for violent offenders with primary diagnosis of personality disorder $(\mathrm{N}=55)$. Additionally, there is an admissions ward with 30 beds.

In Spain, individuals who are declared not criminally responsible on the basis of mental disorders undergo a pre-trial psychiatric assessment, and if they are found to have been suffering from mental illness at the time of the offense, they are sentenced to psychiatric treatment at a Forensic Psychiatric Hospital where they are evaluated at least 
176 twice per year in order to review their progress and modify or maintain their legal

177 status.

178 Participants

179 The sample included all 117 severely mentally ill violent offenders from the ward 180 hosing violent men without physical deterioration. Patients were included in the study if 181 they: (a) were male; (b) had a primary clinical diagnosis of schizophrenia, schizo182 affective disorder, delusional disorder, other psychosis, or bipolar disorder; and (c) had 183 committed at least one violent crime. Of the 117 patients eligible to participate in the study, $12(10.3 \%)$ did not meet diagnoses criteria, 17 (14.5\%) refused to take part, and

$18588(75.2 \%)$ formally consented. Among these $88,22(25.0 \%)$ had presented a history of 186 conduct disorder prior to age 15 and $66(75.0 \%)$ had not. All 88 patients were assessed 187 in the hospital between September 2012 and February 2013 and information was 188 extracted from clinical files that are up-dated every six months with progress reports 189 from a psychiatrist, psychologist, and social worker as required by the court. The 190 patients were aged, on average, 42.9 years $(\mathrm{SD}=9.5)$. Diagnostic and Statistical 191 Manual of Mental Disorders (DSM-IV 4 ${ }^{\text {th }}$ edition; American Psychiatric Association, 192 1994) criteria for schizophrenia were met by $67.0 \%(n=59)$, while $15.9 \%(n=14)$ 193 presented delusional disorder, $8.0 \%(n=7)$ schizo-affective disorder, 3.4\% $(n=3)$ 194 bipolar disorder, and 5.7\% $(\mathrm{n}=5)$ other psychotic disorders. Additionally, 29.5\% 195 ( $\mathrm{n}=26)$ of the sample met criteria for a comorbid diagnosis of personality disorder.

196 Urine tests conducted within the past year when patients returned from outings detected 197 traces of drugs in $9.0 \%(n=8)$ of the participants. The average length of stay at the 198 institution was 151 months ( $\mathrm{SD}=93.23$, range 6-360 months).

199 Measures 

217 judgement.

Socio-demographic characteristics were extracted from hospital files and collected from participants and other informants, primarily family members.

Diagnoses of Severe Mental Illness. The DSM-IV $\left(4^{\text {th }}\right.$ ed $)$ classification criteria for Axis I (American Psychiatric Association, 2000) were used to revise all file diagnoses. Clinical information was corroborated through weekly reports from psychiatrists and psychologists who periodically reviewed each diagnosis and carried out an exhaustive evaluation of the patient's mental state. Given the diverse sources of information and the high degree of consensus among the evaluations, fewer than $5 \%$ of the diagnoses were modified by the researchers.

Convictions and judgements of not guilty by reason of insanity. Information was extracted from official criminal records. Violence was defined as in the HCR-20 manual as actual, attempted or threatened physical harm deliberately to others (Webster et al., 1997). Acts of violence included; homicide, murder, assault, injury, robbery offences involving injury to the victim. According to the Spanish Penal Code (arts. 138-140) it is considered murder when the act coincides with at least one of the following circumstances: treachery, cruelty, or the perpetrator has been hired. The categories of homicide or murder were established based on the information collected from the court

Physical abuse prior to age 15 was documented from patient interviews recorded in clinical files. It was defined as the child having been hit, pushed, kicked, slapped, and any other act resulting in deliberate physical harm. Responses were coded as present (frequently occurred) or absent (occasionally or never).

Hyperactivty. Childhood hyperactivity was defined according to DSM-IV-TR criteria as a persistent pattern of inattention and excessive motor activity present in 
224

225

226

227

more than one setting before age 7 . This information was extracted from hospital files.

When information was unclear or not available, it was coded as absent.

Family history of mental disorders. Information on mental disorders among family members was extracted from files and coded as present, absent or not available.

Family history of criminality Information on criminal convictions or judgments of insanity among fathers, mothers, brothers and sisters was coded as present, absent or not available and collected from hospital files and from participants during interviews.

Violation on rules in the Institution. Information on violation of rules within the hospital was extracted from hospital files and coded as: (a) non-compliance with timetables; (b) not taking medication during outings; (c) possession of prohibited objects in the institution; and (d) minor acts of aggression (including verbal aggression and property damage not resulting in physical harm).

HCR-20. The HCR-20 (Webster et al., 1997) is a tool that uses structured professional judgment (SPJ) to assess risk of violence and factors associated with risk. It is composed of 20 risk factors grouped into 3 domains: Historical (H), Clinical (C) and Risk Management $(\mathrm{R})$ scored on a 3-point scale $(0,1$ or 2$)$ indicating the presence, possible presence or absence of each item. The psychometric properties have been examined in numerous studies reporting rates of moderate to excellent predictive validity (Belfrage, 1998; Douglas \& Reeves, 2010). In a recent Spanish prospective longitudinal study exploring the predictive validity of the HCR-20 and PCL:SV (Hart et al., 1995) in a sample of 78 mentally disordered inpatients followed up for 12 months, the ROC analysis yielded moderate to strong association between HCR-20 and violence (AUCs=.69-.77), PCL:SV (AUCs=.61-.70) (for a review see Arbach-Lucioni, Andrés-Pueyo, Pomarol-Clotet, \& Gomar-Soñez, 2011) . In the present study a random 
248 sample of 16 patients was rated independently by a second experienced psychologist and the intra-class correlation for the total score was high 0.71 .

PCL:SV. The PCL:SV (Hart et al., 1995) consists of 12 items rated on a 3-point scale ranged from 0 to 24 . A cut-off of 18 and above has been recommended to indicate the presence of psychopathy. The psychometric properties of this instrument have been confirmed in numerous studies reporting high correlations with the original scale The Hare Psychopathy Checklist-Revised (PCL-R; Hare, 1991) and adequate cross-cultural reliability (Cooke, Michie, Hart, \& Clark, 2005). The PCL:SV has been shown to be the most appropriate instrument to measure prototypical psychopathic facets in forensic populations (Cooke, \& Michie, 1999) and includes two robust factors that capture the interpersonal/affective and antisocial/unstable behaviour traits of psychopathy. A random sample of 16 patients was rated independently by an experienced psychologist and the intra-class correlation for the total scores was high 0.84 .

The HCR-20 and the PCL-SV were completed by psychologists trained in the use of both instruments for each patient based on information from a clinical interview and files.

Conduct Disorder. Information on childhood characteristics was collected from files and interviews with each participant, using the Conduct Disorder module of the Structured Clinical Interview for DSM-IV (SCID-II) (First, Gibbon, Spitzer, Williams, $\&$ Benjamin, 1997). In addition we used multiple sources of information (medical records, files, and interviews with family members and social workers) to assess symptoms of CD prior to age 15. A diagnosis of CD was coded as present or absent. psychiatric hospital. 
Data were analysed using SPSS for the Social Sciences version 20. Sociodemographic, clinical, criminal histories, and HCR-20 and PCL:SV scores of violent offenders with SMI $+\mathrm{CD}$ and with SMI-CD were compared using chi-square tests for the categorical variables, Student's $t$-tests for normally distributed continuous variables and the Mann-Whitney $U$ for skewed continuous variables. Six forward stepwise logistic regression analyses were then performed to examine the multivariate relationships of scores on HCR-20, PCL:SV and socio-demographic variables with SMI+CD. The dependent variable was coded 0 for participants with SMI-CD and 1 for those with $\mathrm{SMI}+\mathrm{CD}$. Model 1 estimates the independent contribution of the total HCR score to group SMI $+\mathrm{CD}$. Model 2 estimates the independent contribution of the $\mathrm{H}, \mathrm{C}$, and $\mathrm{R}$ scores to SMI+CD, while Model 3 estimates the association of the total PCL:SV score with SMI + CD. Model 4 estimates the independent contribution of the total PCL:SV factor 1 and 2 scores with SMI+CD._Because some of the symptoms of the CD could be captured by the risk assessment instruments, the analyses of these models were conducted leaving out possible confounders (young age at first violent incident and early maladjustment), both part of the H scale of the HCR-20 and juvenile delinquency, part of the PCL: SV. To test the collinearity between confounders, we used the Collin Command in Stata. We found no evidence of collinearity (the mean of variance was 3.05) while a mean variance inflation factor above 10 is considered indicative of significant collinearity (Chen, Ender, Mitchell, \& Wells, 2009).

Finally, models 5 and 6 were computed to determine whether variables that were significantly associated with SMI $+\mathrm{CD}$ and SMI-CD at univariate level $\mathrm{p}<.05$ (current personality disorder, age at first offence, low education level, rule breaking within the institution, and family psychiatric history) were independently associated with SZ+CD, 
297 as opposed to SZ-CD, after controlling in model 5 for the total HCR score and in model 2986 for the PCL:SV score.

299

Comparisons of severely mentally ill offenders with and without Conduct Disorder prior to age 15

Insert Table 1 about here

presented in Table 1. No significant differences were observed regarding age, marital status, primary diagnosis, or family history of mental disorders. Fewer of the

participants with $\mathrm{CD}$ than those without $\mathrm{CD}$, had completed secondary school, more had a co-morbid personality disorder, and a history of substance misuse. Those with $\mathrm{CD}$ prior to age 15 had been first convicted of a criminal offence at a younger age, had acquired more had convictions prior to the judgement of insanity, had experienced

312 physical abuse as a child, presented hyperactivity in childhood, had relatives with

313 mental disorders, acquired a greater number of convictions, and proportionately more of

314 their relatives had a history of criminality. Additionally, proportionately more of those

315 with CD than those without had breached institutional rules.

316 Comparison of HCR-20 and PCL: SV scores of violent offenders with SMI+CD and

317 violent offenders with SMI-CD 
Insert Table 3 about here

The results of the logistic regression analyses are shown in Table 3. In Model 1, the total HCR-20 score was positively associated with SMI+CD. In Model 2, the H score was independently, and positively, associated with SMI $+\mathrm{CD}$, while C scores were independently and negatively associated with $\mathrm{SMI}+\mathrm{CD}$, and the R score was not significantly associated. In Model 3, the total PCL:SV score was significantly associated with SMI+CD. In Model 4, factor 2 scores were positively associated with $\mathrm{SMI}+\mathrm{CD}$, while factor 1 scores showed no association. Six predictor variables were entered into Model 5: total HCR-20 score, personality disorder, age at first offence, low educational level, rule breaking within institution and family psychiatric history. The model indicated that the HCR-20 total scores, a comorbid personality disorder, and low educational level were independently associated with SMI $+\mathrm{CD}$, while age at first offence, rule breaking within institution, and family psychiatric history were not. A final Model included the total PCL:SV score and the significant variables that distinguished the violent offenders with and without $\mathrm{CD}$ at univariate level. The model showed that scores on the PCL:SV and low educational level were significantly associated with $\mathrm{SMI}+\mathrm{CD}$. However, personality disorder, age at first offense, and rule breaking within institution, did not significantly contribute to the regression model. The wide confidence intervals for the odds ratios in these models indicate that these findings should be carefully interpreted. 
346

347

\section{DISCUSSION}

This study compared HCR-20 and PCL: SV scores of violent offenders with SMI with and without a history of CD prior to age 15 . In univariate comparisons, patients with $\mathrm{SMI}+\mathrm{CD}$ as compared to those without $\mathrm{CD}$ were more likely to have been convicted of violent crimes prior to the index offence that lead to the judgement of insanity and to have engaged in breaches of hospital rules. However, in regression models, after taking account of either the HCR-20 score or the PCL:SV score, neither of these factors were associated with SMI+CD.

As hypothesized, violent offenders with SMI+CD obtained higher total HCR-20 scores. Further, in the regression model that included the three HCR sub-scales, the total H scores were independently and positively associated with SMI+CD confirming past studies showing that among men with schizophrenia or SMI the presence of CD prior to age 15 was associated with persistent pattern of criminality through middle age (Hodgins, et al, 2005; Hodgins et al., 2008; Swanson et al., 2006). However, C scores on HCR-20 were negatively associated with SMI+CD, suggesting that these patients were less symptomatic than those with SMI-CD. We hypothesized that these offenders with SMI+CD commit their first offence prior to treatment for psychosis, and they go on to commit more offences than those offenders without CD. However, despite the fact that they are more persistent offenders, they are more clinically stable and they spend less time in the institution due to that they are convicted for less severe violent crimes. However, this hypothesis was not tested due to the small size of the sample. The lack of association of the $\mathrm{R}$ score with $\mathrm{SMI}+\mathrm{CD}$ is also surprising, given the evidence that those with prior $\mathrm{CD}$ are more likely than others to commit future violent crimes and to engage 
370

371

372

373

374

375

376

377

378

379

380

381

382

383

384

385

386

387

388

389

390

391

392

393

394

in aggressive behaviour. The finding may be due to the fact that patients were not being considered for discharge at the time of the study.

In the present study, violent offenders with SMI+CD obtained higher PCL:SV total scores than did violent offenders with SMI-CD. This is similar to a previous finding showing that among forensic patients PCL-R scores correlated with a diagnosis of Antisocial Personality Disorder (Hart \& Hare, 1989). In regression model examining the independent contributions of PCL:SV factors 1 and 2 to SMI+CD or SMI-CD, only factor 2 was found to be associated with SMI+CD. This finding indicates that the elevated PCL:SV scores result from the severity of antisocial/unstable behaviour traits, rather than from the interpersonal/affective traits of psychopathy. These results are also consistent with results from previous studies that demonstrated that factor 2 of PCL:SV is more strongly related to violent offending than factor 1 (Guy, Edens, Anthony, \& Douglas, 2005; Leistico, Salekin, DeCoster, \& Rogers, 2008; Belfrage, Fransson, \& Strand, 2000; Salekin, Rogers, \& Sewell, 1996).

In the present study, primary diagnoses of patients with and without prior $\mathrm{CD}$ were similar, consistent with previous studies (Moran \& Hodgins, 2004), but the proportion of patients with delusional disorder was higher among the violent offenders with no history of $\mathrm{CD}$ than among those with $\mathrm{CD}$. However, this difference was not statistically significant, due to the small number of patients with this diagnosis. In a study conducted in Canada, delusional disorder was found to be much more common among prison inmates than in a sample of patients recruited in a psychiatric hospital (Côté, Lesage, Chawky \& Loyer, 1997). Delusional disorder may be associated with violent behaviour but not surprisingly given the symptoms of the disorder, few studies have examined this possibility. Importantly, almost two-thirds of the violent offenders who had presented CD prior to age 15 received a clinical diagnosis of a personality disorder. Consistent 
395

396

397

with previous studies, proportionately fewer of the violent offenders with SMI+CD than those with SMI-CD completed high school, while proportionately more presented hyperactivity and reported having experienced physical abuse in childhood. Physical abuse is a precursor of both schizophrenia (Bendall, Jackson, Hulert, \& McGorry, 2008; Morgan \& Fisher, 2006; Read, vanOs, Morrison, \& Ross, 2005) and CD (Murray \& Farrington, 2010; Stouthamer-Loeber, Loeber, Homish, \& Wei, 2001; Widom, 1989). Further, the families of the violent offenders with SMI $+\mathrm{CD}$ included proportionately more individuals with criminal convictions and mental disorders, consistent with previous reports (Fazel, Langstrom, Hjern, Grann, \& Lichtenstein, 2009; Hodgins, 2008). In regression models, after taking account of either the HCR-20 or PCL:SV total score, only a comorbid personality disorder and low education were associated with $\mathrm{SMI}+\mathrm{CD}$.

In the present study, proportionately more of the violent offenders with SMI+CD than those with SMI-CD had a history of substance misuse. This is to be expected since prospective longitudinal studies have shown that children and adolescents with $\mathrm{CD}$ are exposed earlier to alcohol and drugs and begin misusing these substances at a young age (Robins \& McEvoy, 1990). Importantly, much evidence now indicates that among individuals who are genetically vulnerable for schizophrenia, heavy cannabis use in early adolescence promotes the onset of psychosis (Di Forti et al., 2012). A recent study of a sample of patients experiencing their first episode of schizophrenia indicated that the presence of $\mathrm{CD}$ increased the likelihood of heavy cannabis use in early adolescence (Malcolm et al., 2011).

\section{Clinical implications}

The results of the present study have relevant clinical implications for mental health services. Among men with severe mental illness antipsychotic medication is 
420

421

422

essential for treating the symptoms of schizophrenia. However, once positive symptoms have been reduced, other factors such as prior $\mathrm{CD}$ and aggressive behaviour continue to be associated with elevated scores on risk assessment tools. In order to reduce violence, strategies are required to change what are life-long patterns of aggressive behaviour. Individuals with schizophrenia and high levels of violence require treatments that promote compliance and reduce their long-standing antisocial and aggressive behaviours. New behaviours and ways of thinking are needed, as are prosocial skills especially problem solving skills. Psychoeducation promotes knowledge of schizophrenia and the necessity of neuroleptic medications. Cognitive-behavioural treatments within institutions show promise in reducing antisocial and aggressive behaviours (for a review see Kolla \& Hodgins, 2013). A recent study showed that prior $\mathrm{CD}$ was associated with a failure to complete such an intervention (Cullen, Soria, Clarke, Dean, \& Fahy, 2011) again highlighting the need for interventions aimed at promoting engagement in treatment in this sub-group of patients. As such interventions are labour intensive and costly, it is essential to identify the patients with SMI+CD who are most in need and likely to benefit from them.

\section{Strengths and limitations}

The study examined a sample of violent offenders with SMI who had been judged not guilty by reason of insanity and sent to treatment in a forensic hospital in Spain. Information was collected from multiple sources including the patients themselves, family members, criminal and medical files. The HCR-20 and PCL:SV were administered and scored by psychologists trained to use these instruments and interrater reliability was high for both. Limitations include the focus on men only, a small sample size not allowing for statistical comparisons, and a lack of clear information about whether childhood hyperactivity was not present or was not assessed. 


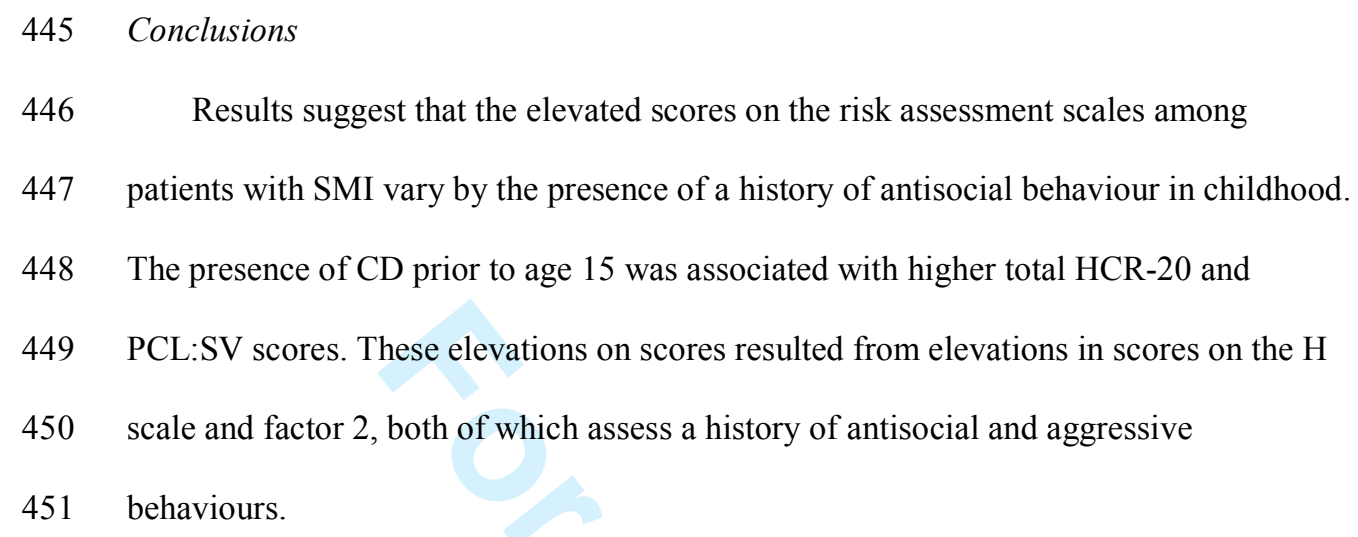

American Psychiatric Association (2000). Diagnostic and Statistical Manual of Mental Disorders (4th ed) (DSM-IV). Washington, DC: American Psychiatric Association. Arbach-Lucioni., Andrés-Pueyo., Pomarol-Clotet, E., \& Gomar-Soñes, J. (2011).

Predicting violence in psychiatric inpatients: a prospective study with the HCR-20 violence risk assessment scheme. The Journal of Forensic Psychiatry \& Psychology, 22(2), 203-222. doi.org/10.1080/14789949.2010.530290

Arseneault, L., Cannon, M., Murray, R., Poulton, R, Caspi, A., \& Moffitt, T. E. (2003). Childhood origins of violent behaviour in adults with schizophreniform disorder. The British Journal of Psychiatry, 183, 520-525. doi: 10.1192/02-485 Belfrage, H., Fransson, G., Strand, S. (2000). Prediction of violence using the HCR-20: 466 
470

471

472 473
Bendall, S., Jackson, H. J., Hulbert, C. A., \& McGorry, P. D. (2008). Childhood trauma and psychotic disorders: A systematic, critical review of the evidence. Schizophrenia Bulletin, 34, 568-579. doi: 10.1093/schbul/sbm121

Chen, X., Ender, P., Mitchell, M., \& Wells, C. (2009). Regression With Stata. http://www.ats.ucla.edu/stat/stata/webbooks/reg/default.htm. Accessed October 21, 2013.

Cooke, D. J., Michie, C., Hart, S. D., \& Clark, D. (2005). Assessing psychopathy in the UK: concerns about cross-cultural generalisability. The British Journal of Psychiatry, 186, 335-341. doi: 10.1192/bjp.186.4.335

Cooke, D. J., \& Michie, C. (1999). Psychopathy across cultures: North America and Scotland compared. Journal of Abnormal Psychology, 108, 58-68. doi: 10.1037/0021843X.108.1.58

Côté, G., Lesage, A., Chawky, N., \& Loyer, M. (1997). Clinical specificity of prison inmates with severe mental disorders: A case-control study. The British Journal of Psychiatry, 170, 571-577 doi: 10.1192/bjp.170.6.571 Cullen, A.E., Soria, C., Clarke, A., Dean, K., \& Fahy, T. (2011). Factors Predicting Dropout From the Reasoning and Rehabilitation Program With Mentally Disordered Offenders. Criminal Justice and Behavior, 38(3), 217-230. doi:10.1177/0093854810393659

Crocker, A. G., Mueser, K. T., Drake, R. E, Clark, R. E., Mchugo, G. J., Ackerson, T. H., \& Alterman, A. I. (2005). Antisocial personality, psychopathy, and violence in persons with dual disorders: A longitudinal analysis. Criminal Justice and Behaviour, 32, 452-476. doi:10.1177/0093854805276407

Di Forti ,M., Iyegbe, C., Sallis, H., Kolliakou, A., Falcone, M.A., Paparelli, A., ...Murray, R.M. (2012). Confirmation that the AKT1 (rs2494732). Genotype
Formatted: Highlight

Formatted: Highlight

Formatted: Highlight

Formatted: Highlight

Formatted: Highlight

Formatted: Highlight 


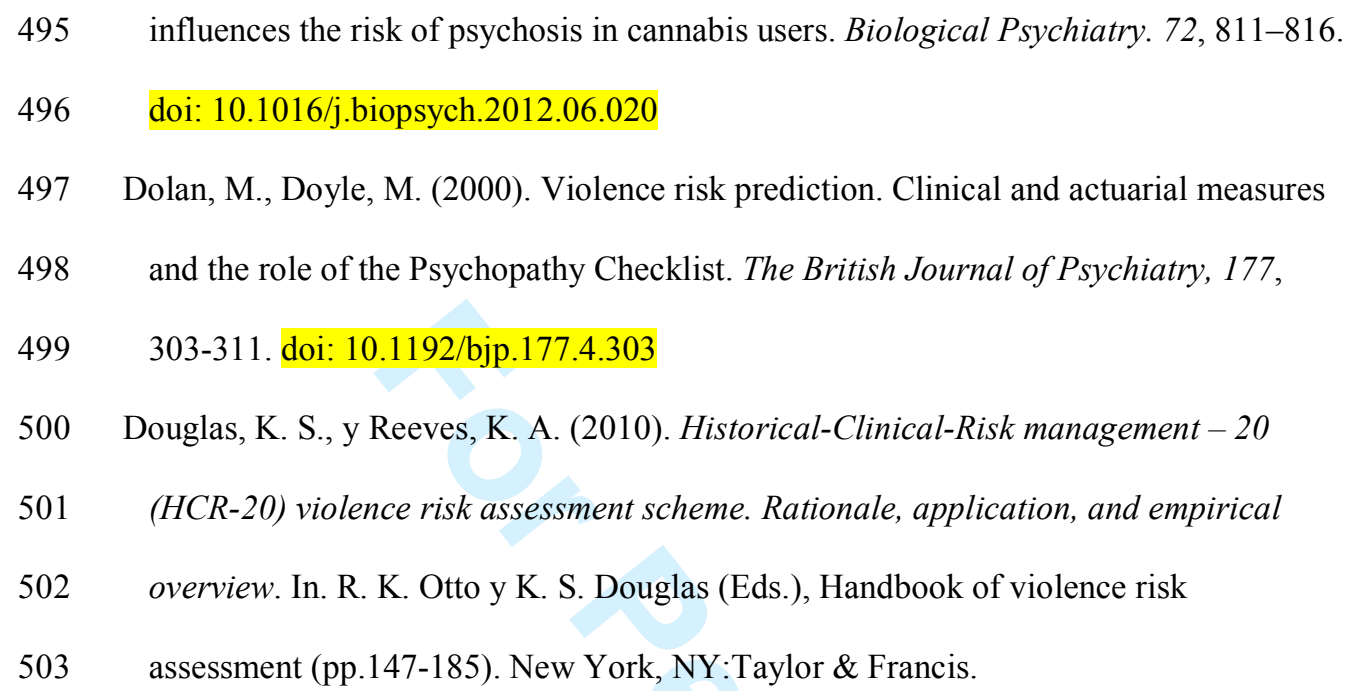


519 Hare, R. D. (1991). The Hare Psychopathy Checklist-Revised. Toronto, Canada: Multi$520 \quad$ Health Systems.

521 Hart, S. D., Cox, N., \& Hare, D. (1995). The Hare Psychopathy Checklist: Screening 522 Version (PCL:SV). Toronto: Multi Health System Inc.

523 Hart, S. D., \& Hare, R. D. (1989). The discriminant validity of the Psychopathy 524 Checklist in a forensic psychiatric population. Psychological Assessment: A Journal of Consulting and Clinical Psychology, 1, 211-218. doi:10.1037/1040-3590.1.3.211

526 Hodgins ,S., \& Côté, G. (1993). Major mental disorder and antisocial personality disorder: A criminal combination. The Bulletin of the American Academy of Psychiatry and Law, 21, 155-160.

Hodgins, S., Côté, G., \& Toupin, J. (1998). Major mental disorders and crime: An etiological hypothesis. In. Cooke D, Forth A, Hare RD (eds) Psychopathy: Theory, research and implications for society. Kluwer Academic Publishers, Dordrecht, p. $231-256$.

Hodgins, S. (2004). Criminal and antisocial behaviours and schizophrenia: A neglected topic. In Gattaz WF \& Häfner H (eds) Search for the causes of schizophrenia, vol V. Steinkopff Verlag, Darmstadt, p 315-341.

Hodgins, S., Tiihonen, J., \& Ross, D. (2005). The consequences of conduct disorder for males who develop schizophrenia: Associations with criminality, aggressive behaviour, substance use, and psychiatric services. Schizophrenia Research, 78, 323335. doi:10.1016/j.schres.2005.05.021

Hodgins, S., Alderton, J., Cree, A., Aboud, A., \& Mak, T. (2007). Aggressive behaviour, victimisation and crime among severely mentally ill patients requiring hospitalisation. The British Journal of Psychiatry, 191, 343-350. doi:

10.1192/bjp.bp.106.06.029587 
544 Hodgins, S., Cree, A., Alderton, J., \& Mak, T. (2008). From conduct disorder to severe 545 mental illness: Associations with aggressive behaviour, crime and victimization.

546 Psychological Medicine, 38, 975-987.

547 doi: http://dx.doi.org/10.1017/S0033291707002164

548 Hodgins, S. (2008). Violent behaviour among people with schizophrenia: A framework 549 for investigations of causes, and effective treatment, and prevention. Philosophical

550 Transaction of the Royal Society of London. Series B Biological Sciences, 363, 2505551 2518. doi: $10.1098 /$ rstb.2008.0034

552 Joyal, C., Putkonen, A., Mancini-Marïe, A., Hodgins, S., Kononen, M., Boulay, L. ...\& 553 Aronen, H. (2007). Violent persons with schizophrenia and comorbid disorders: A 554 functional magnetic resonance imaging study. Schizophrenia Research, 91, 97-102. 555 doi: 10.1016/j.schres.2006.12.014

556 Kim-Cohen, J., Caspi, A., Moffitt, T. E., Harrington, H., Milne, B. J., \& Poulton, R. 557 (2003). Prior juvenile diagnoses in adults with mental disorder developmental follow558 back of a prospective-longitudinal cohort. Archive of General of Psychiatry, 60, 709559 717. doi:10.1001/archpsyc.60.7.709.

560 Kolla, N. \& Hodgins, S. (2013). Treatment of people with schizophrenia who behave 561 violently towards others: A review of the empirical literature on treatment 562 effectiveness (pp. 321-339). In L. A. Craig, L. Dixon, \& T. A. Gannon (Eds). What 563 Work's in Offender Rehabilitation: An evidence based approach to assessment and 564 treatment. United Kingdom: Wiley Blackwell.

565 Leistico, A., Salekin, R., DeCoster, J., \& Rogers, R. (2008). A large-scale meta-analysis 566 relating the Hare measures of psychopathy to antisocial conduct. Law and Human 567 Behavioour, 32, 28-45. 
568 Malcolm, C. P., Picchioni, M. M., DiForti, M., Sugranyes, G., Cooke, E., Joseph, C., 569 ...Hodgins, S. (2011). Pre-morbid conduct disorder symptoms are associated with 570 cannabis use among individuals with a first episode of psychosis. Schizophrenia 571 Research, 126, 81-86. doi.org/10.1016/j.schres.2010.11.025

572 Moffitt, T. E., \& Caspi, A. (2001). Childhood predictors differentiate life-course 573 persistent and adolescence-limited antisocial pathways among males and females.

574 Development and Psychopathology, 13, 355-375.

575 doi.org/10.1017/S0954579401002097

576 Moran, P., \& Hodgins, S. (2004). The correlates of comorbid antisocial personality

577 disorder in schizophrenia. Schizophrenia Bulletin, 30, 791-802.

578 Morgan, C., \& Fisher, H. (2006). Environment and schizophrenia: Environmental 579 factors in schizophrenia: Childhood trauma- a critical review. Schizophrenia Bulletin, $580 \quad 33,3-10$. doi: $10.1093 /$ schbul/sbl053

581 Mueser, K.T., Crocker, A.G., Frisman, L.B., Drake, R.E., Covell, N.H., \& Essock, S.M. 582 (2006). Conduct disorder and antisocial personality disorder in persons with severe 583 psychiatric and substance use disorders. Schizophrenia Bulletin, 32, 626-636.

584 doi: $10.1093 /$ schbul/sbj068

585 Murray, J., \& Farrington, D. (2010). Risk factors for conduct disorder and delinquency: 586 Key findings from longitudinal studies. Canadian Journal of Psychiatry 55, 633-642.

587 Polanczyk, G., Moffitt, T. E., Arseneault, L., Cannon, M., Ambler, A., Keefe, R. S. E., 588 ... \& Caspi, A. (2010). Etiological and clinical features of childhood psychotic 589 symptoms: Results from a birth cohort childhood psychotic symptoms. Archives 590 General of Psychiatry, 67, 328-338. doi: 10.1001/archgenpsychiatry.2010.14 591 Read, J., van Os, J., Morrison, A. P., \& Ross, C. A. (2005). Childhood trauma, 592 psychosis and schizophrenia: A literature review with theoretical and clinical 
593

594

595

596

597

598

599

600

601

602

603

604

605

606

607

608

609

610

611

612

613

614

615

implications. Acta Psychiatrica Scandinava, 112, 330-350. doi: 10.1111/j.1600-

0447.2005.00634.x

Rice, M. E., \& Harris, G. T. (1995). Psychopathy, schizophrenia, alcohol abuse, and violent recidivism. International Journal of Law and Psychiatry, 18, 333-342.

doi.org/10.1016/0160-2527(95)00015-A

Robins, L. N., \& McEvoy, J. P. (1990). Conduct problems as predictors of substance abuse. In Robins LN, Rutter M (eds). Straight and Devious Pathways from Childhood to Adulthood. Cambridge University Press, New York, p 182-204.

Salekin, R., Rogers, R., \& Sewell, K. (1996). A review and meta-analysis of the Psychopathy Checklist and Psychopathy Checklist-Revised: Predictive validity of dangerousness. Clinical Psychology: Science and Practice, 3, 203-215.

doi: $10.1111 / \mathrm{j} .1468-2850.1996 . t b 00071$

Schug, R. A., Raine, A., \& Wilcox, R. R. (2007). Psychophysiological and behavioural characteristics of individuals comorbid for antisocial personality disorder and schizophrenia-spectrum personality disorder. The British Journal of Psychiatry, 191, 408-414. doi: 10.1192/bjp.bp.106.034801

Schanda, H., Földes, P., Topitz, A., Fliedl, R., \& Knecht, G. (1992). Premorbid adjustment of schizophrenic criminal offenders. Acta Psychiatrica Scandinava, 86, 121-126. doi: 10.1111/j.1600-0447.1992.tb03239.x

Schiffer, B., Leygraf, N., Muller, B.W., Scherbaum, N., Forsting, M., Wiltfang, J., ... \& Hodgins, S. (2012). Structural brain alterations associated with schizophrenia preceded by conduct disorder: A common and distinct subtype of schizophrenia? Schizophrenia Bulletin. doi: 10.1093/schbul/sbs115 
616 Stouthamer-Loeber, M., Loeber, R., Homish, D.L., Wei, E. (2001). Maltreatment of 617 boys and the development of disruptive and delinquent behavior. Development and 618 Psychopathology, 13, 941-955.

619 Swanson, J. W., Swartz, M. S., Van Dorn, R. A., Elbogen, E. B., Wagner, R., 620 Rosenheck, R.,... \& Lieberman, J. A. (2006). A national study of violent behavior in 621 persons with schizophrenia. Archives General of Psychiatry, 63, 490-499.

622 Tengström, A., Hodgins, S., Grann, M., Långström, N., \& Kullgren, G. (2004).

623 Schizophrenia and criminal offending: The role of psychopathy and substance use 624 disorders. Criminal Justice and Behavior, 31, 367-391. doi:

$625 \quad 10.1177 / 0093854804265173$

626 Tengström, A., Hodgins, S., \& Kullgren, G. (2001). Men with schizophrenia who 627 behave violently: The usefulness of an early- versus late-start offender typology. 628 Schizophrenia Bulletin, 27, 205-218.

629 Webster, C. D., Douglas, K. S., Eaves, D., \& Hart, S. D. (1997). HCR-20: Assessing 630 Risk for Violence (Version 2). Burnaby, Canada: Mental Health, Law, and Policy 631 Institute, Simon Fraser University.

632 Widom, C. S. (1989). The cycle of violence. Science, 244, 160-166. 
Table1. Comparisons of severely mentally ill violent offenders with and without Conduct Disorder prior to age 15

\begin{tabular}{|c|c|c|c|}
\hline \multicolumn{4}{|c|}{ Violent offender } \\
\hline & $\begin{array}{l}\mathrm{SMI}+\mathrm{CD} \\
(\mathrm{N}=22)\end{array}$ & $\begin{array}{l}\text { SMI-CD } \\
(\mathrm{N}=66)\end{array}$ & Test \\
\hline Age & $\mathrm{M}=41.8 \mathrm{SD}=8.7$ & $\mathrm{M}=43.3 \mathrm{SD}=9.8$ & $\begin{array}{l}\text { Mann-Whitney } U, \mathrm{z}=-5.50, \\
p=0.582\end{array}$ \\
\hline \multicolumn{4}{|l|}{ Marital status $\%$} \\
\hline Single & $15(68.2)$ & $52(78.8)$ & \\
\hline Married & $2(9.1)$ & $5(7.6)$ & \\
\hline Separated/Divorced & $5(22.7)$ & $9(13.6)$ & \\
\hline \multicolumn{4}{|l|}{ Accommodation \% } \\
\hline Living alone & $7(31.8)$ & 13 (19.7) & \\
\hline Couple & $1(4.5)$ & $12(18.2)$ & \\
\hline Family & $9(40.9)$ & $36(54.5)$ & \\
\hline Others & $5(22.5)$ & $5(7.6)$ & \\
\hline \multicolumn{4}{|l|}{ Education level \% } \\
\hline Primary school & $19(86.4)$ & $33(50.0)$ & \\
\hline Secondary education & $3(13.6)$ & $28(42.4)$ & \\
\hline College or above & & $5(7.6)$ & \\
\hline \multicolumn{4}{|l|}{ Primary Diagnosis \% } \\
\hline Schizophrenia & $15(68.2)$ & $44(66.7)$ & \\
\hline Delusional disorders & $1(4.5)$ & $13(19.7)$ & \\
\hline $\begin{array}{l}\text { Schizo-affective- } \\
\text { disorder }\end{array}$ & $2(9.1)$ & $5(7.6)$ & \\
\hline $\begin{array}{l}\text { Other psychotic } \\
\text { disorders }\end{array}$ & $3(13.6)$ & $2(3.0)$ & \\
\hline Bipolar disorder & $1(4.5)$ & $2(3.0)$ & \\
\hline \multicolumn{4}{|l|}{ Comorbidity $\%$} \\
\hline $\begin{array}{l}\text { Current personality } \\
\text { disorder }\end{array}$ & $15(68.2)$ & $11(16.7)$ & $\chi^{2}(n 88)=18.63, p<.001$ \\
\hline $\begin{array}{l}\text { Current substance misuse } \\
\text { History of substance }\end{array}$ & $3(13.6)$ & $5(7.6)$ & \\
\hline misuse & $22(100)$ & $35(53.0)$ & $\chi^{2}(n 84)=14.11, p<.001$ \\
\hline \multicolumn{4}{|l|}{ Criminal history } \\
\hline Mean age at first offense & $\mathrm{M}=27.7 \mathrm{SD}=9.2$ & $\begin{array}{l}M=36.7 \\
S D=12.6\end{array}$ & $\begin{array}{l}\text { Mann-Whitney } U, \mathrm{z}=- \\
2.11, p=0.035\end{array}$ \\
\hline $\begin{array}{l}\text { Rule breaking within the } \\
\text { hospital }\end{array}$ & $14(63.6)$ & $19(28.8)$ & $\chi^{2}(n 88)=7.12, p=0.004$ \\
\hline
\end{tabular}




\begin{tabular}{|c|c|c|c|}
\hline Prior conviction $\%$ & $18(81.80)$ & $14(21.2)$ & $\chi^{2}(n 88)=26.19, p<.001$ \\
\hline For at least one violent-crime & $17(77.3)$ & $13(19.7)$ & $\chi^{2}(n 88)=24.72, p<.001$ \\
\hline $\begin{array}{l}\text { For at least one non-violent } \\
\text { crime }\end{array}$ & $1(4.5)$ & $1(1.5)$ & \\
\hline \multicolumn{4}{|l|}{ Index offences \% } \\
\hline Murder & $4(18.2)$ & $20(30.3)$ & \\
\hline Attempted murder & $1(4.5)$ & $9(13.6)$ & \\
\hline Homicide & $2(9.1)$ & $11(16.7)$ & \\
\hline Attempted homicide & $2(9.1)$ & $11(16.7)$ & \\
\hline Threats & $5(22.7)$ & $2(3.0)$ & \\
\hline Injuries & $1(4.5)$ & $3(4.5)$ & \\
\hline Sexual assault & $1(4.5)$ & $2(3.0)$ & \\
\hline Robbery & $1(4.5)$ & & \\
\hline Other violent offenses & $5(22.6)$ & $8(12)$ & \\
\hline Victim $\%$ & & & $\chi^{2}(n 88)=2.07, p=0.120$ \\
\hline Family member or known & $12(54.5)$ & $47(71.2)$ & \\
\hline Unknown & $10(45.5)$ & $19(28.2)$ & \\
\hline Physical abuse in childhood \% & $10(45.5)$ & $3(4.5)$ & \\
\hline Hyperactivity in childhood \% & $11(50.0)$ & & \\
\hline Family psychiatric history $\%$ & & & $\chi^{2}(n 80)=5.244, p=0.022$ \\
\hline Yes & $14(63.6)$ & $27(40.9)$ & \\
\hline No & $4(18.2)$ & $35(53.0)$ & \\
\hline \multicolumn{4}{|l|}{ Family criminal history $\%$} \\
\hline Yes & $4(18.2)$ & $3(4.5)$ & \\
\hline No & $8(36.4)$ & $55(83.3)$ & \\
\hline Unknown & $10(45.5)$ & $8(12.1)$ & \\
\hline
\end{tabular}

N.B. For some variables, numbers of participants in each cell were too small to allow for statistical comparisons. 
Table 2. Comparisons of HCR-20 and PCL:SV scores of severely mentally ill violent offenders who presented conduct disorder before age 15 and those who did not

\begin{tabular}{rrrrrrll}
\hline \multicolumn{7}{c}{ Violent Offenders } \\
\hline \multicolumn{7}{c}{$\begin{array}{c}\text { SMI+CD } \\
(\mathrm{N}=22)\end{array}$} & $\begin{array}{c}\text { SMI-CD } \\
(\mathrm{N}=66)\end{array}$ \\
& $\mathrm{M}$ & $\mathrm{SD}$ & $\mathrm{M}$ & $\mathrm{SD}$ & $\mathrm{t}(88)$ & $p$ \\
\hline HCR Total & 25.09 & 4.7 & 15.2 & 6.5 & -6.536 & $<.001$ \\
HCR- H & 14.7 & 2.3 & 6.6 & 2.9 & -12.048 & $<.001$ \\
HCR- C & 4.5 & 2.2 & 4.2 & 2.8 & -0.601 & 0.548 \\
HCR- R & 6.4 & 2.6 & 4.4 & 2.2 & -3.406 & $<.01$ \\
PCL:SV Total & 14.4 & 3.3 & 6.7 & 4.1 & -3.749 & $<.001$ \\
Factor 1 & 5.3 & 2.4 & 2.9 & 2.2 & -6.443 & $<.001$ \\
Factor 2 & 9.1 & 1.3 & 3.9 & 2.3 & -5.887 & $<.001$ \\
\hline
\end{tabular}

SMI+CD: severe mental illness and conduct disorder prior to age 15

SMI-CD: severe mental illness with no conduct disorder 
Table 3. Relationship of HCR-20, PCL: SV scores and multiple variables with the presence of conduct disorder before age 15 among violent offenders with severe mental illness.

\begin{tabular}{|c|c|c|c|c|c|}
\hline & $\mathrm{B}$ & $\mathrm{SE}$ & Wald & $p$ & OR (IC 95\%) \\
\hline \multicolumn{6}{|l|}{ Model 1} \\
\hline HCR-20 Total & 0.242 & 0.059 & 16.714 & $<.001$ & $1.27(1.13-1-43)$ \\
\hline \multicolumn{6}{|l|}{ Model 2} \\
\hline HCR-H & 1.800 & 0.550 & 10.705 & .0001 & $6.05(2.06-17.77)$ \\
\hline HCR-C & $-0,983$ & 0.451 & 4.738 & 0.029 & $0.37(0.16-0.91)$ \\
\hline HCR-R & 0.473 & 0.360 & 1.727 & 0.189 & $1.61(0.79-3.25)$ \\
\hline \multicolumn{6}{|l|}{ Model 3} \\
\hline PCL:SV Total & 0.413 & 0.095 & 18.764 & $<.001$ & $1.51(1.25-1.82)$ \\
\hline \multicolumn{6}{|l|}{ Model 4} \\
\hline PCL Factor 1 & $-0,034$ & 0.180 & 0.036 & 0.849 & $0.97(0.68-1.38)$ \\
\hline PCL Factor 2 & 0.912 & 0.222 & 16.389 & $<.001$ & $2.49(1.61-3.85)$ \\
\hline \multicolumn{6}{|l|}{ Model 5} \\
\hline HCR-20 Total & 0.278 & 0.078 & 12.749 & $<.001$ & $1.32(1.13-1.54)$ \\
\hline Personality disorder & 3,384 & 1.322 & 6.553 & 0.010 & $29.50(2.21-393.65)$ \\
\hline Age at first offence & -0.186 & 0.106 & 3.091 & 0.079 & $0.83(0.68-1.02)$ \\
\hline Low education level & 1.805 & 0.843 & 4.587 & 0.032 & $6.08(1.17-31.70)$ \\
\hline Rule breaking institution & 0.264 & 0.752 & 0.123 & 0.725 & $1.30(0.30-5.69)$ \\
\hline $\begin{array}{l}\text { Family Psychiatric } \\
\text { history }\end{array}$ & -1.287 & 1.209 & 1.134 & 0.287 & $0.28(0.03-2.95)$ \\
\hline \multicolumn{6}{|l|}{ Model 6} \\
\hline PCL:SV & 0.532 & 0.145 & 13.383 & $<.001$ & $1.70(1.28-2.26)$ \\
\hline Personality disorder & 3.791 & 3.528 & 3.528 & 0.060 & $44.29(0.85-2313.46)$ \\
\hline Age at first offense & $-0,247$ & 2.609 & 2.609 & 0.106 & $0.78(0.58-1.05)$ \\
\hline Low education level & 2.469 & 1.003 & 6.064 & 0.014 & $11.81(1.66-84.32)$ \\
\hline $\begin{array}{l}\text { Rule breaking institution } \\
\text { Family psychiatric }\end{array}$ & 0.774 & 0.808 & 0.918 & 0.338 & $2.17(0.45-10.56)$ \\
\hline history & $-1,826$ & 0.543 & 0.543 & 0.461 & $0.16(0.00-20.71)$ \\
\hline
\end{tabular}

